\title{
Unemployment and the Labor Share
}

\author{
Sephorah Mangin*, Petr Sedláček**
}

3 Abstract

The labor share fluctuates over the business cycle. To explain this behavior, we develop a novel model featuring direct competition between heterogeneous firms to hire workers. This simultaneously endogenizes both average match productivity and the division of output between workers and firms. In existing matches, wages partly reflect labor market conditions at the time of hiring. A positive TFP shock therefore reduces the aggregate labor share, making it counter-cyclical. However, greater competition and lower unemployment increase labor's share among new firms. As more firms enter, the aggregate labor share rises and eventually overshoots its initial level, as in the data.

4 Keywords: Labor share; Factor shares; Unemployment; Search; Heterogeneous firms

${ }_{5}$ JEL Classification: E23, E24, E25, E32, J64

\footnotetext{
We are indebted to the editor Ricardo Reis and two anonymous referees for suggestions that have significantly improved the paper. We thank Klaus Ackermann for excellent research assistance and we thank seminar participants at the University of Edinburgh, the Chicago Fed, the University of Melbourne, Monash University, ANU, and Deakin University; and conference participants at the Workshop on Macroeconomic Dynamics, the Southern Workshop in Macroeconomics, the North American Winter Meeting of the Econometric Society, and the LAEF Workshop in Sydney. This paper has benefited from particularly useful comments from and discussions with Jeff Campbell, Horag Choi, Andrew Clausen, Pedro Gomis-Porqueras, Greg Kaplan, Ian King, Stephen King, Philipp Kircher, Finn Kydland, Jakob Madsen, John Moore, Bruce Preston, Paul Raschky, Diego Restuccia, Peter Rupert, Raul Santaeulalia-Llopis, Rob Shimer, Lawrence Uren, Randy Wright, and Yves Zenou. Sephorah Mangin acknowledges the Becker Friedman Institute for its hospitality and financial support at an early stage of this project.

*Corresponding author. Department of Economics, Monash University. Address: PO Box 197 Caulfield East Victoria 3145 Australia. Email: sephorah.mangin@monash.edu

** Department of Economics, University of Oxford. Address: Manor Road, OX1 3UQ, Oxford, UK. Email: petr.sedlacek@economics.ox.ac.uk
} 
The relative constancy of the labor share has for decades been seen as a stylized 3 fact in macroeconomics, as evidenced by the widespread usage of the Cobb-Douglas 4 aggregate production function. Recently, however, the labor share has been shown to 5 fluctuate in a cyclical manner. In particular, Rios-Rull and Santaeulalia-Llopis (2010) 6 show that the labor share declines in response to a positive TFP shock - making it 7 counter-cyclical - but this drop quickly reverts and the labor share rises over time, eventually overshooting its initial level. This paper aims to understand the mechanism behind such cyclical movements of the labor share.

Building on the basic framework of Mangin (2017), we develop a dynamic search and matching model in which firms with heterogeneous productivities compete for workers. In contrast to much of the existing literature, which assumes a particular aggregate production function, the model simultaneously endogenizes both wages and average match output. We incorporate both aggregate TFP and investment-specific technology shocks and find that the framework yields rich yet analytically tractable labor market dynamics that are consistent with the data. In particular, we show that the model can account for both the counter-cyclicality of the labor share and its overshooting behavior following an aggregate TFP shock.

Unlike Diamond-Mortensen-Pissarides (DMP) models with bilateral (one-on-one) meetings, a key feature of the model is that a worker may be simultaneously approached by two or more competing firms that directly compete to hire the worker. In such multilateral (many-on-one) meetings, workers are hired by the most productive firm. This endogenizes the average match output, or labor productivity, which is increasing in the market tightness since workers can be more selective when there are more competing firms per worker. At the same time, wages also endogenously reflect the degree of competition at the time of hiring. Specifically, wages in multilateral meetings are equal to 
the productivity of the second most productive firm competing for a worker. Therefore, in our model, production and wage determination are intimately linked. This contrasts with DMP models with Nash bargaining, which rely on using an exogenous bargaining parameter that is unrelated to the production technology.

We assume a Pareto distribution for firm productivity levels, which enables us to analytically characterize the model's dynamics, including those of the aggregate labor share. In steady state, the labor share depends on the degree of competition for workers, the reservation wage, the level of TFP, and the dispersion of firm productivity levels. In particular, we show that the steady state labor share is increasing in the level of TFP provided that the reservation wage is sufficiently responsive - a condition that is satisfied under our calibration. The mechanism is intuitive: higher TFP leads to greater firm entry and lower unemployment, thereby increasing the labor share through stronger competition to hire workers and a higher reservation wage.

This steady state result suggests a positive relationship between aggregate TFP and the labor share. However, we know that the labor share is counter-cyclical in the data. In fact, the full dynamic model can account for both the counter-cyclicality and the overshooting of the labor share. This highlights the importance of studying its dynamics. To understand these dynamics, we need to consider the cohort effects generated by firm competition for workers.

Outside the steady state, matches of various "vintages" coexist in every period. Since both wages and match productivity are determined through the process of direct competition to hire workers, both are influenced by the labor market conditions prevailing at the time of hiring. As a result, the model generates cohort effects that lead to rich dynamics for the labor share. In particular, the aggregate labor share is influenced by the composition of the employment pool with respect to match vintages (i.e. labor market conditions at the time of hiring). The systematic variation in the 
composition of matches of various vintages is key for understanding the dynamics of the aggregate labor share.

In a calibrated version of the model, we show that the aggregate labor share falls in response to a positive TFP shock: the labor share is counter-cyclical. This happens because wages of existing workers are partially rigid, since they reflect the degree of competition at the time of hiring. However, following a positive TFP shock, the degree of competition between firms strengthens and unemployment falls because it is now more attractive to hire workers. This, in turn, endogenously increases the labor share of newly hired workers. Over time, as the composition of matches shifts towards vintages formed in periods of stronger competition, the aggregate labor share rises and eventually reaches a level higher than its initial one: the labor share overshoots.

We also investigate to what extent our model is able to explain the observed time path of the U.S. labor share and how important are the novel features of our model - namely, the competition and cohort effects - for achieving this. To do this, we use the calibrated model and estimate the underlying aggregate shocks using data on real GDP and unemployment. We show that the resulting model-predicted time series for the labor share tracks the data very closely. Importantly, we conduct the same exercise in a variant of our model, which retains the same equilibrium conditions but in which we "switch off" the competition and cohort effects. The resulting time series for the labor share is essentially uncorrelated with its counterpart in the data. Therefore, the model's key features - competition and cohort effects - are crucial for understanding the time series pattern of the labor share that we observe in the data.

Finally, in addition to accounting for the dynamics of the labor share - the key focus of this paper - we show that the calibrated model also performs well in replicating business cycle patterns of other labor market variables. Moreover, the model offers a set of new predictions that are absent in standard search and matching models. While 
of independent interest, these also serve as supporting evidence for the underlying mechanism. First, the model predicts that the wage elasticity with respect to aggregate labor productivity is larger for new hires than for existing workers, which is consistent with the data (see e.g. Bils, 1985; Haefke et al., 2013; Gertler et al., 2016). Second, the model predicts that labor productivity features an overshooting pattern in response to investment-specific shocks, as observed in the data (see e.g. Fisher, 2006; Canova et al., 2013). Finally, a key prediction of the model is the presence of firm and worker cohort effects - driven by aggregate conditions at the time of hiring - which have also been documented in the data (see e.g. Oreopoulos et al., 2012; Sedláček and Sterk, 2017).

There has been a resurgence of interest in the labor share due to its recent trend decline both in the U.S. and globally. In particular, King and Watson (2012) document a sharp fall in the U.S. labor share during the 2000s. Elsby et al. (2013) discuss this recent decline and identify globalization and offshoring as potentially important factors. Karabarbounis and Neiman (2014) document a global decline in the corporate labor share since the early 1980s and attribute this to a fall in the relative price of investment goods. Piketty (2014) and Piketty and Zucman (2014) suggest the labor share decline arises from capital accumulation. This literature follows earlier papers on medium-run changes in the labor share, including Blanchard (1997), who examines the effects of labor market deregulation and changes in the degree of unionization, and Bentolila and Saint-Paul (2003), who consider the effects on the labor share of changes in workers' bargaining power, among other factors.

In contrast to the above studies, this paper focuses on the cyclical fluctuations of the labor share. We do so by extending the static search and matching framework of Mangin (2017) to a dynamic environment with aggregate shocks. The cyclical nature of the labor share has received relatively less attention in the literature. In an earlier contribution, Gomme and Greenwood (1995) argue that optimal labor contracting 
between entrepreneurs and workers can explain the counter-cyclical behavior of labor's 2 share at a quarterly frequency. Recently, Choi and Rios-Rull (2009) and Colciago and 3 Rossi (2015) suggest that, in addition to non-competitive wages, deeper insight into 4 the nature of the production technology may be necessary to understand both the 5 counter-cyclicality and the overshooting of the labor share. While the former study a 6 search and matching model with a C.E.S. production function, the latter consider a 7 model with counter-cyclical markups.

The remainder of this paper is structured as follows. Section 2 presents the model 9 and derives expressions for the dynamics of unemployment, output, and the labor share. It provides a description of the wage determination mechanism and expressions for wages and factor shares for arbitrary distributions of firm productivities, before specializing to the Pareto distribution. Section 3 establishes the existence and uniqueness of the steady state equilibrium and derives some comparative statics results. In

\footnotetext{
Section 4, we calibrate the model and present the quantitative results and analysis. Section 5 concludes. All proofs are found in the Appendix. ${ }^{1}$
}

\section{Model}

There is an infinite number of discrete time periods. In each period, there is a continuum of homogeneous risk-neutral workers of measure $L$. At the start of period $t$, there is a continuum of measure $U_{t}$ of unemployed workers and a continuum of riskneutral potential firms. The measure of entering firms is $V_{t}$ and the ratio of entering firms to unemployed workers is $\phi_{t}=V_{t} / U_{t}$. Both workers and firms discount future payoffs using a discount factor $\beta \in(0,1)$.

To enter, potential firms must pay a cost $C_{t}$, the cost of purchasing one unit of capital. We interpret exogenous shocks to $C_{t}$ as investment-specific technology shocks.

\footnotetext{
${ }^{1}$ The Appendix is available online on the journal's website.
} 
1 After paying the $\operatorname{cost} C_{t}$, all firms search for a worker.

Firms approach unemployed workers at random. For the sake of tractability, work3 ers who are already employed cannot be targeted by firms: there is no on-the-job 4 search. After meeting with a worker, firms privately draw an idiosyncratic permanent 5 match-specific productivity $x$ from a distribution with $\operatorname{cdf} G(x){ }^{2}$

6 Assumption 1. The underlying distribution of firm productivities has cdf $G(x)$, pdf $7 g(x)$, support $\left[x_{\min }, \infty\right)$ where $x_{\min } \geq 0$, a finite mean, and no mass points.

Not all matches may be acceptable for both workers and firms: only matches with permanent productivity $x \geq x_{t}^{c}$ for some cut-off productivity $x_{t}^{c}$ are accepted by both workers and firms in period $t$. Firms with productivity $x \geq x_{t}^{c}$ will compete to hire workers; firms with productivity $x \leq x_{t}^{c}$ exit immediately. $^{3}$

The labor market tightness $\theta_{t}$ is defined as the ratio of competing firms to unemployed workers, $\theta_{t} \equiv \phi_{t}\left(1-G\left(x_{t}^{c}\right)\right)$. The number of competing firms approaching a given unemployed worker in period $t$ is a Poisson random variable with parameter $\theta_{t}$. If a firm with permanent productivity $x$ hires a worker, the match produces output in period $t$ equal to $A_{t} x$ where $A_{t}$ is an exogenous shock that hits the economy at the start of period $t$. We refer to $A_{t}$ as an aggregate TFP shock.

Matches are destroyed at the start of each period at an exogenous rate $\delta \in(0,1]{ }^{4}$ For tractability, we assume that once a worker and a firm agree to form a match, it can only terminate through exogenous match destruction. ${ }^{5}$ When a match is destroyed, the worker becomes unemployed and the firm's capital is destroyed.

Since the number of firms competing for each worker is a Poisson random variable, any given meeting between workers and firms can be either bilateral (i.e. exactly one

\footnotetext{
${ }^{2}$ If firms draw productivities before deciding whether to search for a worker, the results are identical.

${ }^{3}$ We show in the Appendix that there exists a unique cut-off productivity $x_{t}^{c}$ such that all matches with permanent productivity $x \geq x_{t}^{c}$ are acceptable to both workers and firms in period $t$.

${ }^{4}$ Match destruction applies to matches existing at the start of the previous period, not new hires.

${ }^{5}$ In the calibrated version of our model, we verify that the surplus of all matches is always positive.
} 
competing firm) or multilateral (i.e. two or more competing firms).

In a multilateral meeting in period $\tau$, firms compete to hire the worker. The highest productivity firm hires the worker and in each period $t \geq \tau$ until match destruction it produces output $A_{t} x^{1}$ where $x^{1}$ is the permanent productivity of the most productive firm. Since there are competing offers, the worker is paid $A_{t} x^{2}$ where $x^{2}$ is the permanent productivity of the second most productive firm competing for that worker.

In a bilateral meeting in period $\tau$, where the firm has permanent productivity $x$, the firm hires the worker and in each period $t \geq \tau$ until match destruction it produces output $A_{t} x$. Since the worker has no other wage offers, he is simply paid his reservation wage $b_{\tau}$ at the time of hiring each period until match destruction.

If no firms approach an unemployed worker in period $t$, he receives the value of non-market activity $z \in\left[0, x_{\text {min }}\right]$ and stays unemployed. For simplicity, we assume that a firm's capital is destroyed when it is unsuccessful in hiring.

The timing of events within each period $t$ can be summarized as follows: $(i)$ aggregate shocks $A_{t}$ and $C_{t}$ hit the economy and exogenous match destruction occurs; (ii) potential firms make an entry decision and pay the cost $C_{t} ;($ iii $)$ search takes place and meetings between firms and workers occur; $(i v)$ firms draw idiosyncratic permanent match-specific productivities and compete for workers; and $(v)$ successful firms hire workers, produce output, pay wages, and earn profits.

\subsection{Unemployment, productivity, output, and factor shares}

Since the number of competing firms targeting each unemployed worker during period $t$ is a Poisson random variable with parameter $\theta_{t}$, the meeting technology is urn-ball and therefore the matching probability for unemployed workers and competing firms respectively is $m\left(\theta_{t}\right)=1-e^{-\theta_{t}}$ and $q\left(\theta_{t}\right) \equiv m\left(\theta_{t}\right) / \theta_{t}$.

The measure of unemployed workers $U_{t}$ at the start of period $t$ evolves according to the following standard law of motion: 


$$
U_{t+1}=U_{t}\left(1-m\left(\theta_{t}\right)\right)+\delta\left(L-U_{t}\right)
$$

1 and the measure of employed workers $N_{t}$ at the start of period $t$ evolves according to

$$
N_{t+1}=(1-\delta) N_{t}+m\left(\theta_{t}\right) U_{t}
$$

2 The measure of existing matches that survive match destruction at the start of period ${ }_{3} t+1$ is $(1-\delta) N_{t}$ and the measure of new hires created in period $t$ is $h_{t} \equiv m\left(\theta_{t}\right) U_{t}$. ${ }_{4}$ The unemployment rate $u_{t}$ at the start of period $t$ is given by $u_{t}=U_{t} / L$.

\section{2.1.1. Endogenous match output}

$6 \quad$ In any given period, workers who are initially unemployed will either form a match 7 with permanent productivity $x$ or they will remain unemployed and produce zero out8 put that period. We can derive the endogenous distribution of permanent match pro9 ductivities $x$ across workers who are initially unemployed at the start of period $t$.

10 First, we define the (truncated) distribution of productivities among competing 11 firms, $G_{t}^{c}(x) \equiv \operatorname{Pr}\left(X<x \mid x \geq x_{t}^{c}\right)$. The minimum of this distribution is $x_{0 t} \equiv$ $12 \max \left\{x_{\min }, x_{t}^{c}\right\}$ since only firms with productivity greater than $x_{t}^{c}$ compete.

13 Suppose that $n$ firms compete to hire a given worker in period $t$. The cdf of a 14 worker's output conditional on $n$ firms competing is $H_{t}(x \mid n)=\left(G_{t}^{c}(x)\right)^{n}$, the distri15 bution of the maximum of $n$ draws from $G_{t}^{c}(x)$. To obtain $H_{t}\left(x ; \theta_{t}\right)$, the endogenous 16 distribution of productivities $x$ across all workers initially unemployed at time $t$, the 17 conditional cdf $H_{t}(x \mid n)$ is weighted by the Poisson probability that $n$ firms compete:

$$
H_{t}\left(x ; \theta_{t}\right)=\sum_{n=0}^{\infty} \frac{\theta_{t}^{n} e^{-\theta_{t}}}{n !}\left(G_{t}^{c}(x)\right)^{n}=e^{-\theta_{t}\left(1-G_{t}^{c}(x)\right)}
$$

18 The distribution $H_{t}\left(x ; \theta_{t}\right)=e^{-\theta_{t}\left(1-G_{t}^{c}(x)\right)}$ automatically builds in the possibility of 
1 unemployment, since the mass point at $x=0$ with probability mass $1-m\left(\theta_{t}\right)=e^{-\theta_{t}}$ 2 represents initially unemployed workers who remain unemployed (i.e. who are not 3 matched at time $t)$. We can also define $H_{t}^{e}\left(x ; \theta_{t}\right) \equiv\left(H_{t}\left(x ; \theta_{t}\right)-e^{-\theta_{t}}\right) / m\left(\theta_{t}\right)$, the 4 distribution of productivities across workers who are newly employed at time $t$.

${ }_{5} \quad$ We can define $p\left(\theta_{\tau}\right) \equiv E_{H_{t}^{e}}(x)$, the expected permanent productivity of a worker/firm 6 match created at time $\tau$, given by

$$
p\left(\theta_{\tau}\right)=\int_{x_{0}}^{\infty} x d H_{\tau}^{e}\left(x ; \theta_{\tau}\right) .
$$

7

8

Since $p\left(\theta_{\tau}\right) \equiv E_{H_{\tau}^{e}}(x)$ where $H_{\tau}^{e}\left(x ; \theta_{\tau}\right)$ is defined above, expected match productivity depends on labor market conditions at the time $\tau$ of match creation. This includes both the cut-off productivity $x_{\tau}^{c}$ and the market tightness $\theta_{\tau}$, which affect match productivity though two different channels. Greater market tightness means greater competition between firms to hire workers, which allows workers to be more selective regarding firms and increases the average match productivity. A greater cut-off productivity $x_{\tau}^{c}$ means that only more productive firms enter, increasing the average match productivity.

\subsubsection{Aggregate output}

With aggregate productivity shocks, the output of a match at time $t$ is $A_{t} x$ where $x$ is the permanent component of match productivity and $A_{t}$ is the aggregate TFP shock at time $t$. The expected output at time $t$ across all matches formed in period $\tau$ is given by $A_{t} p\left(\theta_{\tau}\right)$. We call this the labor productivity of cohort $\tau$.

Aggregate output $Y_{t}$ during period $t$ is given by the following:

$$
Y_{t}=A_{t} \sum_{a=0}^{\infty} v_{t, t-a} p\left(\theta_{t-a}\right)
$$

where $v_{t, t-a} \equiv(1-\delta)^{a} h_{t-a}$, the cohort measure at time $t$ of matches of age $a$ that are still active. The expression for aggregate output $Y_{t}$ weights the labor productivity 
${ }_{1} A_{t} p\left(\theta_{t-a}\right)$ for matches created during period $t-a$ by the cohort measure $v_{t, t-a}$. The 2 model has "vintage" features since matches of age $a$ are permanently affected by the 3 labor market conditions at the time of hiring.

\section{2.1.3. Aggregate labor share}

${ }_{5} \quad$ Letting $\widetilde{w}_{t, \tau}$ be the average wage during period $t$ for a worker hired during time $\tau$,

6 the average labor share $\tilde{s}_{L, t, \tau}$ during period $t$ for matches created during time $\tau$ is

$$
\tilde{s}_{L, t, \tau}=\frac{\widetilde{w}_{t, \tau}}{A_{t} p\left(\theta_{\tau}\right)} .
$$

7 The aggregate labor share $s_{L, t}$ during time $t$ is therefore

$$
s_{L, t}=\frac{\sum_{a=0}^{\infty} v_{t, t-a} \widetilde{w}_{t, t-a}}{Y_{t}} .
$$

8 We can also express the aggregate labor share as a weighted average of the cohort$9 \quad$ specific labor shares $s_{L, t, \tau}$.

10 Let $\tilde{v}_{t, \tau}$ be the output share at time $t$ of cohort $\tau$,

$$
\tilde{v}_{t, \tau}=\frac{v_{t, \tau} A_{t} p\left(\theta_{\tau}\right)}{Y_{t}}
$$

11 Clearly, we have $\sum_{a=0}^{\infty} \tilde{v}_{t, t-a}=1$. Substituting (8) into (7) and using (8), we have

$$
s_{L, t}=\sum_{a=0}^{\infty} \tilde{v}_{t, t-a} s_{L, t, t-a} .
$$

12 That is, the aggregate labor share is a weighted average of the cohort-specific labor 13 shares $s_{L, t, \tau}$, where each cohort $\tau$ is weighted by its output share $\tilde{v}_{t, \tau}$. 
2 Letting $V_{t}^{u}$ be the value of unemployment at time $t$, the expected value $V_{t, \tau}^{e}$ of 3 employment in period $t$ in a match formed during period $\tau$ is

$$
V_{t, \tau}^{e}=\tilde{w}_{t, \tau}+\beta\left((1-\delta) \mathbb{E}_{t} V_{t+1, \tau}^{e}+\delta \mathbb{E}_{t} V_{t+1}^{u}\right)
$$

${ }_{4}$ and the value of unemployment $V_{t}^{u}$ is given by

$$
V_{t}^{u}=m\left(\theta_{t}\right) V_{t, t}^{e}+\left(1-m\left(\theta_{t}\right)\right)\left(z+\beta \mathbb{E}_{t} V_{t+1}^{u}\right)
$$

${ }_{5} \quad$ Letting $J_{t, \tau}$ be the expected value in period $t$ of a filled vacancy when the match 6 was created in period $\tau$, we have

$$
J_{t, \tau}=A_{t} p\left(\theta_{\tau}\right)-\widetilde{w}_{t, \tau}+\beta(1-\delta) \mathbb{E}_{t} J_{t+1, \tau}
$$

7 Since $q\left(\theta_{\tau}\right)$ is the probability a competing firm successfully hires a worker, the value ${ }_{8} V_{\tau}$ of an unfilled vacancy (at the time of entry $\tau$ ) is

$$
V_{\tau}=-C_{\tau}+\left(1-G\left(x_{\tau}^{c}\right)\right) q\left(\theta_{\tau}\right) J_{\tau, \tau}
$$

9 2.3. Wage determination

10 In this environment, both the permanent match productivity and wages depend crucially on whether or not there is direct competition to hire the worker at the time of match creation, i.e. on whether the meeting is bilateral or multilateral. Since the number of firms approaching a given worker is a Poisson random variable with parameter $\theta$, whether a worker faces a bilateral or a multilateral meeting is random. However, the proportion of bilateral meetings, $\mu(\theta) \equiv \theta e^{-\theta} / m(\theta)$, is endogenous. Since $\mu^{\prime}(\theta)<0$, greater firm competition implies a lower share of bilateral meetings. 
$1 \quad$ Suppose a worker is hired in a bilateral meeting (i.e. exactly one competing firm) in 2 period $\tau$. The worker is simply paid his reservation wage $b_{\tau}$ every period until match 3 destruction. The reservation wage $b_{\tau}$ is the lowest wage offer the worker is willing to 4 accept: it satisfies the indifference condition (14) that equates the expected payoff from 5 accepting the wage offer and rejecting it. That is,

$$
V_{\tau, \tau}^{1}\left(b_{\tau}\right)=z+\beta \mathbb{E}_{\tau} V_{\tau+1}^{u}
$$

${ }_{6}$ where the value $V_{t, \tau}^{1}(w)$ at time $t$ of being employed at wage $w$ in a bilateral match 7 formed in period $\tau$ is

$$
V_{t, \tau}^{1}(w)=w+\beta\left((1-\delta) \mathbb{E}_{t} V_{t+1, \tau}^{1}(w)+\delta \mathbb{E}_{t} V_{t+1}^{u}\right)
$$

8 The expected value at time $t$ of the filled vacancy with permanent productivity $x$ 9 that was created in a bilateral meeting during period $\tau$ is

$$
J_{t, \tau}^{1}(x)=A_{t} x-b_{\tau}+\beta(1-\delta) \mathbb{E}_{t} J_{t+1, \tau}^{1}(x)
$$

10 Suppose a worker is hired in a multilateral meeting (i.e. two or more competing 11 firms) in period $\tau$. The firm with the highest productivity $x$ hires the worker and 12 pays a wage equal to the second-highest productivity, indexed by the aggregate TFP 13 shock $A_{t}$, each period until match destruction. ${ }^{6}$ More precisely, the expected value of employment in period $t$ in a match with permanent productivity $x$ for a worker hired in a multilateral meeting in period $\tau$ is

$$
V_{t, \tau}^{2}(x)=w_{t, \tau}^{2}\left(A_{t} x\right)+\beta\left((1-\delta) \mathbb{E}_{t} V_{t+1, \tau}^{2}+\delta \mathbb{E}_{t} V_{t+1}^{u}\right)
$$

\footnotetext{
${ }^{6}$ This wage determination mechanism is similar to Bertrand competition or second-price auctions. For a more detailed microfoundation and a discussion of the relevant literature see Mangin (2015).
} 
1 where $w_{t, \tau}^{2}\left(A_{t} x\right)$ is the expected wage in period $t$. The expected value of employment 2 in period $t$ in any match formed in a multilateral meeting in period $\tau$ is

$$
V_{t, \tau}^{2}=\tilde{w}_{t, \tau}^{2}+\beta\left((1-\delta) \mathbb{E}_{t} V_{t+1, \tau}^{2}+\delta \mathbb{E}_{t} V_{t+1}^{u}\right),
$$

${ }_{3}$ where $\tilde{w}_{t, \tau}^{2}$ is the expected wage at time $t$ for a worker hired in such a meeting. The 4 expected value at time $t$ of the filled vacancy with permanent productivity $x$ that was 5 created in a multilateral meeting during period $\tau$ is

$$
J_{t, \tau}^{2}(x)=A_{t} x-w_{t, \tau}^{2}\left(A_{t} x\right)+\beta(1-\delta) \mathbb{E}_{t} J_{t+1, \tau}^{2}(x) .
$$

$6 \quad$ In the Appendix, we verify that for all $t$ there exists a unique cut-off productivity $7 x_{t}^{c}$ such that all matches formed in period $t$ with $x \geq x_{t}^{c}$ are accepted by both workers 8 and firms, and we show that $x_{t}^{c}$ satisfies $J_{t, t}^{1}(x)=0$.

\section{2.3.1. Expected wages and labor share}

10 Firm profits consist of both productivity rents and matching rents, as discussed in 11 Mangin (2015). In the dynamic setting here, we derive in the Appendix the following expression for the expected value of a filled vacancy:

$$
J_{t, \tau}=\underbrace{\pi_{t, \tau}\left(\theta_{\tau}\right)}_{\text {productivity rents }}+\underbrace{\mu\left(\theta_{\tau}\right)\left(A_{t} x_{0 \tau}-b_{\tau}\right)}_{\text {matching rents }}+\beta(1-\delta) \mathbb{E}_{t} J_{t+1, \tau},
$$

13 14

15

where $\mu\left(\theta_{\tau}\right)$ is the share of bilateral meetings at time $\tau$, and $\pi_{t, \tau}\left(\theta_{\tau}\right)$ is the expected value of productivity rents at time $t$ for a match formed in period $\tau$, defined by

$$
\pi_{t, \tau}\left(\theta_{\tau}\right) \equiv \int_{A_{t} x_{0 \tau}}^{\infty}\left(\frac{1-G_{t, \tau}(y)}{y g_{t, \tau}(y)}\right) y d H_{t, \tau}^{e}\left(y ; \theta_{\tau}\right),
$$

where $G_{t, \tau}(y) \equiv G_{\tau}^{c}\left(y / A_{t}\right)$, and $H_{t, \tau}^{e}\left(y ; \theta_{\tau}\right) \equiv H_{\tau}^{e}\left(y / A_{t} ; \theta_{\tau}\right)$. 
$1 \quad$ Productivity rents $\pi_{t, \tau}\left(\theta_{\tau}\right)$ arise because successful firms receive the difference be2 tween the highest and second highest productivity among the firms competing to hire 3 the worker at time $\tau$ of hiring, multiplied by the current TFP shock $A_{t}$. The expected 4 value of the productivity rents available to firms depends on properties of the under5 lying distribution $G$ and is captured by (21). When there is no heterogeneity in firm 6 productivities, i.e. when $G(x)$ is degenerate, $\pi_{t, \tau}\left(\theta_{\tau}\right)=0$.

$7 \quad$ Matching rents reflect the flow match surplus for the least productive firm. Even 8 if a competing firm has the lowest possible productivity $x_{0 \tau}$, it can still earn profits if 9 matched with a worker in a bilateral meeting. The value of matching rents in period $10 t$ for matches created in period $\tau$ is $A_{t} x_{0 \tau}-b_{\tau}$, which is reflected in the second term 11 inside the brackets in (20). With aggregate productivity shocks, matching rents can in 12 principle be either positive or negative in period $t$ depending on the realization of the 13 shock $A_{t}$. When $A_{t} x_{0 \tau}-b_{\tau}=0$, there are no matching rents.

$14 \quad$ Using (12) and (20), expected wages $\widetilde{w}_{t, \tau}$ at time $t$ of a match created at time $\tau$ is

$$
\widetilde{w}_{t, \tau}=\underbrace{A_{t} p\left(\theta_{\tau}\right)}_{\text {expected match output }}-\underbrace{\pi_{t, \tau}\left(\theta_{\tau}\right)}_{\text {productivity rents }}-\underbrace{\mu\left(\theta_{\tau}\right)\left(A_{t} x_{0 \tau}-b_{\tau}\right)}_{\text {matching rents }} .
$$

15 Next, using (6), the labor share $\tilde{s}_{L, t, \tau}$ at time $t$ for matches created in period $\tau$ is

$$
\tilde{s}_{L, t, \tau}=1-\underbrace{\frac{\pi_{t, \tau}\left(\theta_{\tau}\right)}{A_{t} p\left(\theta_{\tau}\right)}}_{\text {productivity rents }}-\underbrace{\frac{\mu\left(\theta_{\tau}\right)\left(A_{t} x_{0 \tau}-b_{\tau}\right)}{A_{t} p\left(\theta_{\tau}\right)}}_{\text {matching rents }},
$$

where $p\left(\theta_{\tau}\right)$ is given by (4). In expression (23), productivity rents and matching rents 17 are expressed as a share of match output. Using (7), the aggregate labor share is 


$$
s_{L, t}=1-\underbrace{\frac{\sum_{a=0}^{\infty} v_{t, t-a} \pi_{t, t-a}\left(\theta_{t-a}\right)}{Y_{t}}}_{\text {productivity rents }}-\underbrace{\frac{\sum_{a=0}^{\infty} v_{t, t-a} \mu\left(\theta_{t-a}\right)\left(A_{t} x_{0 t-a}-b_{t-a}\right)}{Y_{t}}}_{\text {matching rents }} .
$$

$1 \quad$ Essentially, the aggregate capital share $s_{K, t}$ at time $t$ is equal to the sum of both 2 productivity rents and matching rents earned by firms in each cohort $\tau=t-a$, weighted 3 by the relevant cohort measure $v_{t, t-a}$ and then expressed as a share of output. The 4 aggregate labor share is $s_{L, t}=1-s_{K, t}$, which is given by (24).

\section{2.3.2. Equilibrium definition}

$6 \quad$ We can now present a formal definition of an equilibrium.

7 Definition 1. Given exogenous stochastic processes for the two aggregate shocks $A_{t}$ and $C_{t}$, an equilibrium is a sequence $\left\{\phi_{t}, x_{t}^{c}, b_{t}, U_{t}\right\}$ which satisfies

- the free entry condition, $V_{t, t}=0$, i.e. $C_{t}=\left(1-G\left(x_{t}^{c}\right)\right) q\left(\theta_{t}\right) J_{t, t}$,

- the firm indifference condition, $J_{t, t}^{1}\left(x_{t}^{c}\right)=0$,

- the worker indifference condition, $V_{t, t}^{1}\left(b_{t}\right)=z+\beta \mathbb{E}_{t} V_{t+1}^{u}$, and

- the law of motion (1) for unemployment $U_{t}$,

where $\theta_{t}=\phi_{t}\left(1-G\left(x_{t}^{c}\right)\right), J_{t, t}$ is given by (20), $J_{t, t}^{1}(x)$ is given by (16), $V_{t, t}^{1}(w)$ is given by (15), and $V_{t}^{u}$ is given by (11).

\subsection{Pareto distribution}

To obtain tractable expressions for aggregate output, wages, and factor income shares we focus on the Pareto distribution $G(x)$. Let $G(x)=1-x^{-1 / \lambda}$ for $x \in[1, \infty)$ and $G(x)=0$ otherwise. The parameter $\lambda \in(0,1)$ is called the shape parameter and it governs the degree of productivity dispersion. For simplicity, we assume that $\lambda$ is constant. Both the mean and the variance of $G(x)$ are increasing in $\lambda$. 
$1 \quad$ Given the reservation wage $b_{t}$, the (truncated) distribution of competing firms' 2 permanent productivity levels, $G_{t}^{c}(x)$, remains Pareto, $G_{t}^{c}(x)=1-\left(\frac{x}{x_{0 t}}\right)^{-1 / \lambda}$ where ${ }_{3} x_{0 t} \equiv \max \left\{1, x_{t}^{c}\right\}$. For the Pareto distribution, we have

$$
H_{t}\left(x ; \theta_{t}\right)=\left\{\begin{array}{cc}
e^{-\theta\left(\frac{x}{x_{0 t}}\right)^{-1 / \lambda}} & \text { if } x \in\left[x_{0 t}, \infty\right) \\
e^{-\theta_{t}} & \text { otherwise }
\end{array}\right.
$$

${ }_{4}$ Except for the mass point at zero, the distribution $H_{t}\left(x ; \theta_{t}\right)$ is a similar to a Type II ${ }_{5}$ Extreme Value Distribution or Fréchet distribution. This is useful because it means 6 that the distribution of realized match productivities is approximately Fréchet - a 7 distribution that is often used to represent the firm productivity distribution.

$8 \quad$ We now present the specific expressions for wages and the labor share for the Pareto 9 distribution using the general expressions found in Section 2.3.1. These expressions

$$
\widetilde{w}_{t, \tau}=\underbrace{(1-\lambda) A_{t} p\left(\theta_{\tau}\right)}_{\text {expected output minus productivity rents }}-\underbrace{\mu\left(\theta_{\tau}\right)\left(A_{t} x_{0 \tau}-b_{\tau}\right)}_{\text {matching rents }} .
$$
become very tractable because the Pareto distribution has the useful property that $\pi_{t, \tau}\left(\theta_{\tau}\right)=\lambda A_{t} p\left(\theta_{\tau}\right)$ for all $t$ and $\tau$. That is, a firm's expected productivity rents are a constant fraction $\lambda$ of expected match output. In the absence of matching rents, this property would lead to constancy of the labor share. However, in the presence of matching rents, the labor share fluctuates over the business cycle.

The Pareto distribution allows us to decompose the labor share into two components: a constant part (due to productivity rents) and a variable part (matching rents). First, substituting $\pi_{t, \tau}\left(\theta_{\tau}\right)=\lambda A_{t} p\left(\theta_{\tau}\right)$ into (22) yields 


$$
\tilde{s}_{L, t, \tau}=1-\underbrace{\lambda}_{\text {productivity rents }}-\underbrace{\frac{\mu\left(\theta_{\tau}\right)\left(A_{t} x_{0 \tau}-b_{\tau}\right)}{A_{t} p\left(\theta_{\tau}\right)}}_{\text {matching rents }},
$$

1 Substituting $\pi_{t, \tau}\left(\theta_{\tau}\right)=\lambda A_{t} p\left(\theta_{\tau}\right)$ into (24), the aggregate labor share $s_{L, t}$ at time $t$ is

$$
s_{L, t}=1-\underbrace{\lambda}_{\text {productivity rents }}-\underbrace{\frac{\sum_{a=0}^{\infty} v_{t, t-a} \mu\left(\theta_{t-a}\right)\left(A_{t} x_{0 t-a}-b_{t-a}\right)}{Y_{t}}}_{\text {matching rents }} .
$$

2 Since average productivity rents are a constant fraction of output, the aggregate labor 3 share simply equals a constant term $1-\lambda$ minus the sum of matching rents - weighted 4 by the relevant cohort measure - as a share of output. This decomposition makes it 5 clear that it is matching rents that drive the fluctuations in the labor share.

$6 \quad$ Labor's share $s_{L, t}$ is constant (i.e. depends only on the parameter $\lambda$ ) in a given 7 period $t$ if and only if $x_{\tau}^{c} \geq x_{\min }$ and therefore $x_{0 \tau}=x_{\tau}^{c}$, and, in addition $x_{\tau}^{c}=b_{\tau} / A_{t}$ for 8 all cohorts $\tau$. In this case, the value of matching rents, $A_{t} x_{0 \tau}-b_{\tau}$, is always zero and 9 labor's share is constant because the average productivity rents are linear in output.

Clearly, this extreme case is not possible in the presence of aggregate TFP shocks. Even for a given cohort $\tau$, labor's share $s_{L, t, \tau}$ can only be constant in rare periods where matching rents, $A_{t} x_{0 \tau}-b_{\tau}$, are zero. Therefore, with TFP shocks, both the aggregate labor share and cohort-specific labor shares always fluctuate over time.

\section{Steady state}

Consider a stationary environment where $A_{t}=A, z_{t}=z$ and $C_{t}=C$ for all $t$. Let $U_{t+1}=U_{t}=U$ and $\theta_{t+1}=\theta_{t}=\theta$ for all $t$. Let $G(x)=1-x^{-1 / \lambda}$ for $x \in[1, \infty)$ and $G(x)=0$ otherwise, i.e. $x_{\min }=1$. Given the reservation wage $b$, the distribution of competing firms' productivity levels is $G^{c}(x)=1-\left(\frac{x}{x_{0}}\right)^{-1 / \lambda}$ where $x_{0}=\max \left\{1, x^{c}\right\}$. 
1 In the steady state, we have $J_{1}\left(x^{c}\right)=0$ if and only if $x^{c}=b / A .^{7}$

2 Steady state average match productivity is

$$
p(\theta)=\frac{x_{0} \gamma(1-\lambda, \theta) \theta^{\lambda}}{1-e^{-\theta}},
$$

3 where $\gamma(s, x)$ is the Lower Incomplete Gamma Function defined by $\gamma(s, x) \equiv \int_{0}^{x} t^{s-1} e^{-t} d t .{ }^{8}$

4 Average match productivity $p(\theta)$ is increasing in $\theta$ (taking $b$ as given). Since the Pareto 5 distribution is well-behaved, this follows from Lemma 2 in Mangin (2017).

$6 \quad$ Steady state output is given by

$$
Y=\frac{A x_{0} \gamma(1-\lambda, \theta) \theta^{\lambda} U}{\delta} .
$$

7 We can interpret expression (30) as an aggregate production function. To under8 stand it better, consider the special case where $\delta=1$ and $b \leq A$. Since each firm has one 9 unit of capital, $K=V$ in this case and $U=L$, so we have $Y=A \gamma(1-\lambda, \theta) K^{\lambda} L^{1-\lambda}$. In 10 the limit where $\theta \rightarrow \infty$ and unemployment disappears, this function is asymptotically

${ }_{11}$ Cobb-Douglas, $Y=A \Gamma(1-\lambda) K^{\lambda} L^{1-\lambda}$, where $\Gamma(s)$ is the Gamma function. ${ }^{9}$

\subsection{Steady state factor shares}

Steady state labor share $s_{L}$ is

$$
s_{L}=1-\lambda-\frac{\mu(\theta)\left(A x_{0}-b\right)}{A p(\theta)} .
$$

Steady state factor shares are "constant" (i.e. depend only on $\lambda$ ) in two special

\footnotetext{
${ }^{7}$ Using $(16), J^{1}(x)=(A x-b) /(1-\beta(1-\delta))$ and hence $J^{1}(x)=0$ if and only if $x=b / A$.

${ }^{8}$ See the Appendix for some useful properties of the function $\gamma(s, x)$.

${ }^{9}$ This limiting aggregation result is related to Jones (2005), who derives a Cobb-Douglas aggregate production function using a Pareto distribution of ideas. Lagos (2006) also derives a Cobb-Douglas aggregate production function using the Pareto distribution in a Mortensen-Pissarides style searchtheoretic model with random matching and Nash bargaining. See Mangin (2017) for details.
} 
cases. First, there is an asymptotic result: factor shares are constant in the limit as $2 \theta \rightarrow \infty$ and unemployment disappears. In this case, all firms face direct competition 3 and the probability of receiving matching rents disappears because the share of bilateral 4 meetings goes to zero, i.e. $\mu(\theta) \rightarrow 0$. Second, factor shares are constant when $x_{0}=b / A$. ${ }_{5}$ Since $x_{0}=\max \left\{1, x^{c}\right\}$, this means that factor shares are constant when $x^{c}=b / A \geq$ ${ }_{6} x_{\min }=1$, i.e. when $b \geq A$. In this case, the value of matching rents disappears since $7 A x_{0}-b=0$. While the first case cannot arise as an equilibrium outcome, the second 8 case can in principle arise as an equilibrium outcome. ${ }^{10}$

$9 \quad$ The constancy of steady state factor shares in both special cases arises from the

fact that $\pi(\theta)=\lambda A p(\theta)$. That is, productivity rents - equal to the expected difference between the highest and the second highest productivity among competing firms are a constant fraction of the expected match output. ${ }^{11}$ This result applies only in the steady state. As discussed in Section 2.4, the existence of aggregate productivity shocks $A_{t}$ implies that factor shares always fluctuate regardless of the reservation wage.

Lemma 1. Steady state labor share is increasing in the degree of firm competition $\theta$.

In general, steady state labor share is increasing in the degree of firm competition, as measured by the market tightness $\theta$ (taking $b$ as given). Intuitively, as the number of competing firms per unemployed worker $\theta$ rises, greater competition leads to an increase in labor's share. In particular, the share of bilateral meetings is lower $\left(\mu^{\prime}(\theta)<0\right)$ so the probability of direct competition to hire a worker is greater. At the same time, average match productivity $p(\theta)$ increases and therefore $\mu(\theta) / p(\theta)$ is decreasing in $\theta$.

It is clear that labor's share is increasing in the reservation wage $b$ (taking $\theta$ as

\footnotetext{
${ }^{10}$ In Section 3.2, we will see that this is because as $\theta \rightarrow \infty$ and hence $\phi \rightarrow \infty$, we have $b_{r}(\phi)>\bar{b}$ but $\phi_{r}(b)=0$ when $b>\bar{b}$.

${ }^{11}$ Importantly, this property is unique to the Pareto distribution. If $G(x)$ is not Pareto, this is not the case and therefore factor shares are not constant when $b \geq A$. For example, in the Appendix we derive an expression for the steady state labor share using the Generalized Pareto Distribution.
} 
1 given) since in bilateral meetings workers are paid more when their reservation wage is 2 higher, thereby decreasing the value of the matching rents, $A x_{0}-b$, available to firms.

\section{3.2. Steady state equilibrium}

${ }_{4} \quad$ A steady state equilibrium can be characterized by a triple $(\phi, b, U)$ that satisfies ${ }_{5}$ Definition 1 where $x^{c}=b / A$ and $\theta=\phi\left(1-G\left(x^{c}\right)\right)$.

$6 \quad$ For the Pareto distribution, the zero profit condition for firms is

$$
C=\frac{x_{0}^{-1 / \lambda} q(\theta)\left(\pi(\theta)+\mu(\theta)\left(A x_{0}-b\right)\right)}{1-\beta(1-\delta)} .
$$

7 In the Appendix, we show that Assumption 2 implies that there is a critical value ${ }_{8} \bar{b}(\lambda, \beta, \delta, C)>z$ such that for any $b<\bar{b}$, there exists a unique level of firm entry $9 \phi>0$ which satisfies (32). If $b \geq \bar{b}$, there is no firm entry and hence $\phi=\theta=0$. So for any given $b \geq 0$, there is a unique level of firm entry $\phi$ and we have a function $\phi_{r}: \mathbb{R}^{+} \rightarrow \mathbb{R}^{+}$. When $b<\bar{b}$, this function is differentiable and we show that $\phi_{r}^{\prime}(b)<0$. Since $\phi=0$ when $b \geq \bar{b}, \phi_{r}$ is weakly decreasing in $b$.

Assumption 2. The cost of purchasing capital is not too high:

$$
C<\frac{1}{1-\beta(1-\delta)}\left(\frac{A}{1-\lambda}-z\right) .
$$

Let $V^{u}$ be the steady state value of unemployment and let $V^{1}(w)$ be the steady state value of employment at wage $w$ in a bilateral meeting. In a bilateral meeting, unemployed workers will accept a job offer at wage $w$ if $V^{1}(w) \geq z+\beta V^{u}$ and reject it otherwise. In the Appendix, we verify that for any given $\phi \geq 0$, there exists a unique reservation wage $b$ that satisfies the indifference condition:

$$
V^{1}(b)=z+\beta V^{u} .
$$

19 So we have a function $b_{r}: \mathbb{R}^{+} \rightarrow \mathbb{R}^{+}$, and we verify that $b_{r}^{\prime}(\phi)>0$ for all $\phi$. 
1 Substituting $V^{1}(b)$ and $V^{u}$ from (15) and (11), into (34) yields the following ex2 pression for the steady state reservation wage,

$$
b=\frac{z(1-\beta(1-\delta))+\beta(1-\delta) w(\theta, b)}{1-\beta(1-\delta) e^{-\theta}},
$$

${ }_{3}$ where $w(\theta, b) \equiv \tilde{w} m(\theta)$. The reservation wage $b$ is a weighted average of the flow

4 value $z$ of non-market activity and the expected wage for all workers (including the 5 unemployed). It is clear from (35) that when $\phi=\theta=0$, we have $b_{r}(0)=z$.

6 Proposition 1. There is a unique steady state equilibrium $\left(\phi^{*}, b^{*}\right)$ where $z \leq b^{*}<\bar{b}$.

$7 \quad$ We know that for any given $\phi \geq 0$, (34) has a unique solution $b_{r}(\phi)$. At the same

8 time, we know that for any given $b<\bar{b}$, (32) has a unique solution $\phi_{r}(b)$, and if $b \geq \bar{b}$ 9 we have $\phi_{r}(b)=0$. Since the function $b_{r}$ is increasing in $\phi$, and $\phi_{r}$ is decreasing in $b$, 10 there exists a unique steady state equilibrium $\left(\phi^{*}, b^{*}\right)$ that satisfies both (34) and (32).

11 Since $b_{r}(0)=z$ and $b_{r}^{\prime}(\phi)>0$, we have $b_{r}(\phi) \geq z$ for all $\phi$.

\subsection{Comparative statics}

Proposition 2 contains some comparative statics results regarding the effects of the key parameters - the value of non-market activity $z$, the cost of purchasing capital $C$, and the shape parameter $\lambda$ from the underlying productivity distribution - on the equilibrium $\left(\phi^{*}, b^{*}\right)$, as well as on the steady state equilibrium unemployment rate, $u^{*} \equiv u\left(\theta^{*}\right)$, output per capita $y^{*} \equiv Y / L$, and labor productivity $p^{*} \equiv Y / N$. We focus on the case where $b^{*} / A<x_{\min }=1$ and therefore $x_{0}=1$ and $\theta^{*}=\phi^{*}$ because we are primarily interested in the behavior of factor shares.

Proposition 2. If $b^{*}<x_{\min }$, then: $(i)$ workers' reservation wage $b^{*}$ is increasing in $\lambda, z$, and $A$, and decreasing in $C$; $(i i)$ the labor market tightness $\theta^{*}$ is decreasing in $z$ and $C$, and increasing in $\lambda$ and $A$; (iii) the unemployment rate $u^{*}$ is increasing in both $z$ and $C$, and decreasing in $\lambda$ and $A$; (iv) output per capita is decreasing in $z$ and $C$, and increasing in $\lambda$ and $A$; and $(v)$ labor productivity $p^{*}$ is decreasing in $z$ and $C$, and increasing in $\lambda$ and $A$. 
Intuitively, an increase in the value of non-market activity $z$ leads to a direct increase 2 in the reservation wage and a resulting decrease in the market tightness. An increase 3 in the cost of capital $C$ leads to a decrease in the market tightness as less firms enter, 4 resulting in a decrease in the reservation wage. In both cases, less firm competition 5 results in higher unemployment as well as lower labor productivity and lower output 6 per capita. By contrast, in increase in the level of TFP $A$ leads to an increase in the 7 reservation wage and an increase in the market tightness. In this case, greater firm 8 competition results in lower unemployment as well as higher labor productivity and 9 higher output per capita. The effects of a change in the shape parameter $\lambda$ are subtle.

Propositions 3, 4, and 5 provide some comparative statics for the labor share.

Proposition 3. Steady state labor share $s_{L}^{*}$ is increasing in the flow value of nonmarket activity $z$.

An increase in the value of non-market activity $z$ leads to an increase in the reservation wage, which has a positive direct effect on the labor share. There is also a negative indirect effect on the labor share through the labor market tightness, since a higher $z$ decreases the level of firm entry, which has a negative impact on the labor share. Overall, the positive effect dominates and the labor share is increasing in $z$.

Proposition 4. Steady state labor share $s_{L}^{*}$ is decreasing in the capital cost $C$.

19

thi for .

\subsubsection{Effect on labor share of an increase in TFP}

An increase in the level of TFP $A$ influences the steady state labor share through two distinct channels. The first is through $\theta^{*}$. Since $\theta^{*}$ is increasing in $A$ by Proposition 
12 , and $\mu(\theta) / p(\theta)$ is decreasing in $\theta$ by Lemma 1 , there is a positive effect on labor share 2 through $\theta^{*}$. The second is through the term $b^{*} / A x_{0}$ in (31). If this term increases 3 when $A$ does, there is a positive impact on labor share. If this term decreases when $A$ 4 does, there is a negative impact on labor share. Overall, the effect of $A$ on labor share 5 depends on the degree of sensitivity of the reservation wage $b^{*}$ to changes in $A$.

6 7

Before presenting a result regarding the effect of a change in the level of TFP $A$ on the equilibrium labor share, we define some terms. Let $\varepsilon_{b^{*}}(A)$ be the elasticity of $b^{*}$ with respect to $A$, let $\varepsilon_{\theta^{*}}(A)$ be the elasticity of $\theta^{*}$ with respect to $A$, and let $\eta_{\varepsilon}(\theta)$ be the elasticity of $\mu(\theta) / p(\theta)$ with respect to $\theta .{ }^{12}$

Proposition 5. The equilibrium labor share $s_{L}^{*}$ is increasing in the level of TFP A if and only if the reservation wage is sufficiently responsive to $A$ :

$$
\varepsilon_{b^{*}}(A)>\frac{A}{b^{*}}\left(\frac{A x_{0}-b^{*}}{A x_{0}}\right) \varepsilon_{\theta^{*}}(A) \eta_{\varepsilon}\left(\theta^{*}\right)+1
$$

Since $\mu(\theta) / p(\theta)$ is decreasing in $\theta$, we have $\eta_{\varepsilon}\left(\theta^{*}\right)<0$ while $\varepsilon_{\theta^{*}}(A)>0$, so a sufficient condition for labor share $s_{L}^{*}$ to be increasing in $A$ is that $\varepsilon_{b^{*}}(A)>1$. Using the calibration in Section 4, we find that condition (36) holds at the steady state equilibrium. In fact, we find that $\varepsilon_{b^{*}}(A)=1.41$, so the sufficient condition easily holds. Therefore, the steady state equilibrium labor share is increasing in TFP.

Later, when we calibrate the model and describe its dynamics in Section 4, we will see that this is similar to the impact of a positive TFP shock on new hires, but the effect on existing matches is different. As we will see, the different effects of a TFP shock on new vs existing matches gives rise to rich dynamics for the labor share.

\subsubsection{Effect on labor share of a change in distribution $G$}

We now consider the effect on the steady state equilibrium labor share of a change in the underlying productivity distribution $G$. For the Pareto distribution, we can

\footnotetext{
${ }^{12}$ In the Appendix, we provide analytic expressions for $\varepsilon_{b^{*}}(A), \varepsilon_{\theta^{*}}(A)$, and $\eta_{\varepsilon}\left(\theta^{*}\right)$.
} 
2 for the degree of firm heterogeneity or productivity dispersion. ${ }^{13}$

3 When $b \geq A$, we have $s_{L}=1-\lambda$ and labor's share is clearly decreasing in $\lambda$.

4 However, when $b<A$ the net effect is ambiguous. We can decompose the net effect into

${ }_{5}$ two opposing effects. For simplicity, we express it in terms of capital share, $s_{K}^{*}=1-s_{L}^{*}$.

$$
\frac{d s_{K}^{*}}{d \lambda}=\underbrace{\underbrace{\frac{d}{d \lambda}(\lambda)}_{<0 \text { matching rents }}+(A x_{0}-b^{*} \underbrace{\frac{d}{d \lambda} \frac{\mu\left(\theta^{*}\right)}{A p\left(\theta^{*}\right)}}_{<0} \underbrace{-\frac{\partial b^{*}}{\partial \lambda}}_{<0} \frac{\mu\left(\theta^{*}\right)}{A p\left(\theta^{*}\right)}}_{>0 \text { productivity rents }} .
$$

The productivity rents earnt by firms, as a share of output, are clearly increasing in $\lambda$. For the Pareto distribution, productivity rents as a share of output are simply equal to the tail index parameter $\lambda$. This is intuitive: greater firm heterogeneity implies a greater expected value of the difference between the highest and second highest productivity, as a share of output.

The overall effect of $\lambda$ on matching rents, as a share of output, is negative. First, $\partial b^{*} / \partial \lambda>0$ by Proposition 2 , so the impact on matching rents through $b^{*}$ is negative. Intuitively, workers increase their reservation wage when $\lambda$ increases, which decreases the value of matching rents, $A x_{0}-b^{*}$, available to firms. Second, we have

$$
\frac{d}{d \lambda} \frac{\mu\left(\theta^{*}\right)}{A p\left(\theta^{*}\right)}=\underbrace{\overbrace{\partial \theta^{*}}^{>0} \frac{\overbrace{\partial}^{\partial \lambda} \frac{\mu\left(\theta^{*}\right)}{\partial \theta}}{A p\left(\theta^{*}\right)}}_{<0 \text { indirect effect }}+\underbrace{\frac{\partial}{\partial \lambda} \frac{\mu\left(\theta^{*}\right)}{A p\left(\theta^{*}\right)}}_{<0 \text { direct effect }} .
$$

Since equilibrium market tightness $\theta^{*}$ is increasing in $\lambda$ by Proposition 2 , and $\mu(\theta) / p(\theta)$ is decreasing in $\theta$ according to Lemma 1, there is a negative indirect effect on matching

\footnotetext{
${ }^{13}$ Strictly speaking, an increase in $\lambda$ is not a mean-preserving spread in $G$ since it increases both the mean and variance. We have verified numerically, however, that the comparative static results are the same if we normalize $x_{\min }=1-\lambda$ so that an increase in $\lambda$ is a true mean-preserving spread.
} 
1 rents of an increase in $\lambda$ through $\theta$. The direct effect of an increase in $\lambda$ on matching 2 rents is also negative since the denominator is increasing in $\lambda$.

3 Overall, the net effect on labor's share of an increase in $\lambda$ depends on the relative 4 size of the opposing effects on productivity rents and matching rents. Proposition 54 of Mangin (2017) provides a sufficient condition for equilibrium labor share to be 6 increasing in $\lambda$ in a static setting: the value of matching rents cannot be too high. If 7 this condition is satisfied, the positive effect on productivity rents of an increase in the 8 parameter $\lambda$ dominates the negative effect on matching rents. However, this condition 9 only applies in a static environment where $b^{*}=z$. In this case, $\partial b^{*} / \partial \lambda$ equals zero and

the second component of matching rents in (37) disappears.

In a dynamic environment where the reservation wage $b^{*}$ is endogenous, the effect of $\lambda$ on labor's share is more complicated because the value of matching rents, $A x_{0}-b^{*}$, is also endogenous. We cannot obtain simple analytical results; however, using the calibration described in Section 4, we find that expression (37) is positive and therefore the steady state equilbrium labor share is decreasing in the parameter $\lambda$.

\section{Dynamics over time and in response to shocks}

In this section, we analyze the model quantitatively with a particular focus on labor share dynamics. Section 4.1 describes the calibration and the model's performance along several dimensions related to the labor market. The remaining sections describe the model's dynamics, zooming in on the behavior of the labor share. Section 4.2 describes the model's dynamics using impulse response functions (IRFs) to the two aggregate shocks. Section 4.3 considers the business cycle fluctuations in the labor share and, in particular, its dynamics following TFP shocks. Finally, Section 4.4 examines to what extent the model can account for the observed time path of the U.S. labor share. To do this, we use our calibrated model to estimate the underlying shocks. 
3 is assumed to be one month. We set the discount factor to 0.996, resulting in an

4 annual interest rate of about 4 percent. The minimum value of the firm productivity

${ }_{5}$ distribution is normalized to $x_{\min }=1$. The shape parameter $\lambda$ is crucial for determining

6 the endogenous productivity distribution and we therefore set $\lambda$ such that the degree

7 of productivity dispersion among active firms displays a $90-10$ percentile range of

8 0.84, the midpoint between the empirical estimates in Syverson (2004).

9 In order to pin down the separation rate $\delta$, the value of non-market activity $z$, and

10

the average cost of capital $\bar{C}$ (which is assumed to be paid in units of output), we target a steady state unemployment rate of 5.8 percent, a labor share of 68 percent, and a job finding probability of $45 \%$. We use data from Rios-Rull and Santaeulalia-Llopis (2010) who construct a measure of the labor share for the period 1954Q1 to 2004Q4. The values for the unemployment rate, taken from the Bureau of Labor Statistics, and the job finding probability, computed by Shimer (2005), are averages over this period. Note that this calibration procedure does not take a stand on the value of the replacement rate, for which there is little consensus in the literature. The replacement rate implied by our calibration is about $35 \%$ of average wages $(z=0.32)$, which is similar to values in e.g. Shimer (2005), Elsby and Michaels (2013), and Jung and Kuester (2015).

We consider two aggregate shocks: a TFP shock $A_{t}$ and a shock to $C_{t}$. Since each firm owns a unit of capital, the mass of existing firms also represents the capital stock and the number of startups represents capital investment. Therefore, we assume that capital costs are paid in units of output and we interpret shocks to $C_{t}$ as investmentspecific technology shocks along the lines of e.g. Fisher (2006) and Lopez-Salido and 
1 Michelacci (2007). Both aggregate shocks are assumed to follow an AR(1) process. ${ }^{14}$

2 The persistence and standard deviations of the two aggregate shocks are set such that

3 the model replicates the persistence and volatility of output and labor productivity in

4 the data. ${ }^{15}$ This calibration results in the investment-specific technology shocks being

5 about 4.5 times as large as TFP shocks, in line with empirical estimates for the U.S.

6 economy (see e.g. Justiniano and Primiceri, 2008).

$7 \quad$ Table 2 documents the business cycle statistics resulting from the above calibra-

8 tion. It shows that the model does relatively well in capturing both the volatility

9 of unemployment and the job finding probability relative to labor productivity, while

the variation of vacancies is about 40 percent of that observed in the data. The comovement of labor market variables in the model is consistent with the data, including a strong Beveridge curve relationship.

\subsection{Aggregate labor market dynamics}

Figure 1 shows the IRFs of several model variables to expansionary one-standarddeviation shocks to both TFP and investment-specific technology. Following a positive TFP shock (an increase in $A_{t}$ ), all employment relationships become more productive, raising aggregate output and increasing the incentives to post vacancies (top and middle right panels). This is reflected in an increase in the probability of finding a job and a decrease in the probability of filling a vacancy (bottom panels) and it ultimately results in a fall in unemployment (middle left panel).

The same pattern is true also for an expansionary investment-specific technology shock (a decrease in $C_{t}$ ). However, this shock "only" makes new employment relationships cheaper to start up; it does not increase the productivity of existing matches.

\footnotetext{
${ }^{14}$ While the mean of the aggregate TFP shock is normalized to one, investment-specific technology shocks have a mean equal to the steady state capital cost $\bar{C}$.

${ }^{15}$ Labor productivity is measured as real output per worker in the non-farm business sector for the period of 1954Q1 to 2004Q4.
} 
1 Therefore, the output response to this shock is muted (top right panel).

2 The above discussion shows that the aggregate labor market dynamics of the model 3 are similar to those of a standard Diamond-Mortensen-Pissarides model. However, our 4 model incorporates novel features - the competition and cohort effects - which deliver 5 richer dynamics. In particular, average labor productivity is not simply equal to the 6 aggregate TFP shock $A_{t}$, but it is influenced by the composition of the employment 7 pool with respect to firm-specific productivity levels and labor market conditions at 8 the time of hiring. Figure 2 shows the qualitatively different impact the two aggregate 9 shocks have on the dynamics of labor productivity.

10 While labor productivity increases and falls back to its steady state in a standard 11 fashion following an aggregate TFP shock, it initially falls in response to an expan12 sionary investment-specific technology shock. The reason for this initial drop is that cheaper capital promotes hiring and increases the average productivity of new hires due to greater competition. However, the shock leaves unchanged the productivity of existing matches, which dominate the economy initially. The increase in employment combined with only a moderate rise in average match productivity results in aggregate labor productivity falling in the first several quarters. Only after a sufficiently large mass of new hires accumulates does aggregate labor productivity also rise.

Importantly, this initially negative response of labor productivity to investmentspecific shocks has been documented in existing studies (see e.g. Fisher, 2006; Canova et al., 2013). The mechanism behind these patterns rests on the presence of worker and firm cohort-effects driven by aggregate conditions at the time of hiring. Such cohort effects have also been recently documented in the data. For example, Sedláček and Sterk (2017) document that startups born during aggregate downturns remain smaller than their counterparts born in booms even after several years of existence. In addition, Oreopoulos et al. (2012) show that college graduates experience a 9 percent earnings 
loss when they graduate in a recession, an effect largely due to unemployment "shocks" experienced that year. We find that the above wage penalty is about 7 percent in our model. ${ }^{16}$

\subsection{Business cycle dynamics of the labor share}

The labor share is counter-cyclical in the data. Moreover, Rios-Rull and SantaeulaliaLlopis (2010) document that upon a positive TFP shock, the labor share initially drops but then overshoots after about five quarters before eventually settling back to its steady state. ${ }^{17}$ It is this overshooting behavior that has proven difficult to understand through the lens of standard real business cycle and search and matching models.

In the calibrated version of our model, as in the data, the labor share is countercyclical. The correlation coefficient of the (logged and HP-filtered) labor share with aggregate output is -0.39 , while it is -0.22 in the data. As in standard search and matching models, this happens because wages are somewhat rigid. In our model, this rigidity is not ad-hoc but micro-founded and stems from the fact that wages partly reflect labor market conditions via competition at the time of hiring. In addition to being counter-cyclical, the labor share in the model also lags output, as in the data. The correlation coefficient peaks for an output lead of four quarters with a value of 0.4 both in the model and the data.

Importantly, the model can account not only for the counter-cyclicality of the labor share but also its overshooting behavior. Figure 3 shows that the labor share drops upon impact of a positive TFP shock, but then rises quickly above its steady state level after about six quarters, i.e. the labor share overshoots. The timing of the

\footnotetext{
${ }^{16}$ The wage penalty described in Oreopoulos et al. (2012) is based on defining a recession as a period of time during which unemployment increases by 5 percentage points. Following this methodology, we compute the model-predicted wage penalty by simulating our model and averaging the wage differential of newly hired workers (compared to the aggregate) in periods when the unemployment rate rises by 5 percentage points.

${ }^{17}$ All empirical properties of the labor share are taken from Rios-Rull and Santaeulalia-Llopis (2010).
} 
overshooting behavior is almost identical to that in the data. Moreover, the magnitude

2 of the response is also realistic, with the labor share dropping to about -0.2 percent 3 on impact and peaking at about 0.2 percent in the data. ${ }^{18}$

\section{4.3.1. Labor share for new hires and existing matches}

5 The reason behind the labor share dynamics lies in the changing composition of 6 the employment pool with respect to aggregate conditions at the time of hiring. To 7 understand the labor share dynamics, we consider separately the roles of new hires and 8 existing matches, i.e. those hired after and before the shock hit the economy.

Suppose that a positive TFP shock hits the economy in period T. Let $\alpha_{t, T} \equiv$ $10 \sum_{a=0}^{t-T} \tilde{v}_{t, t-a}$, the total output share of new hires (i.e. those hired post-shock). For new 11 hires, we can define $\hat{v}_{t, \tau} \equiv \tilde{v}_{t, \tau} / \alpha_{t, T}$, the output share of cohort $\tau$ among new hires. ${ }_{12}$ For existing matches (i.e. those hired pre-shock), we can define $\bar{v}_{t, \tau} \equiv \tilde{v}_{t, \tau} /\left(1-\alpha_{t, T}\right)$, 13 the output share of cohort $\tau$ among existing matches. Rewriting (9), we have

$$
s_{L, t}=\alpha_{t, T} \underbrace{\sum_{a=0}^{t-T} \hat{v}_{t, t-a} s_{L, t, t-a}}_{\text {labor share of new hires }}+\left(1-\alpha_{t, T}\right) \underbrace{\sum_{a=t-T+1}^{\infty} \bar{v}_{t, t-a} s_{L, t, t-a}}_{\text {labor share of existing workers }} .
$$

That is, the aggregate labor share is a weighted average of the labor shares for new hires and existing matches, which are themselves weighted averages of the cohortspecific labor shares $s_{L, t, \tau}$. The output share of new hires $\alpha_{t, T}$ measures the relative strength of the effects of a shock on new hires versus existing matches.

Since $x_{0 \tau}=1$ in our calibration, we can express the labor share for cohort $\tau$ as:

$$
s_{L, t, \tau}=1-\lambda-\left(1-\frac{b_{\tau}}{A_{t}}\right) \frac{\mu\left(\theta_{\tau}\right)}{p\left(\theta_{\tau}\right)}
$$

\footnotetext{
${ }^{18}$ The unconditional volatility of the labor share relative to that of labor productivity is somewhat larger in the model than in the data (0.79 in the model compared to 0.52 in the data).
} 
For any given cohort of $\tau<T$ of existing matches (pre-shock), all terms except for $2 A_{t}$ are determined by aggregate conditions at the time of hiring $\tau$, i.e. prior to the 3 realization of the shock. Therefore, the impact of the shock is determined solely by the 4 direct effect of $A_{t}$ through the term $b_{\tau} / A_{t}$ and the labor share of existing workers falls. ${ }_{5} \quad$ For any given cohort $\tau \geq T$ of new hires (post-shock), the effect of the TFP shock 6 is complex. For example, consider the effect on the labor share of matches created 7 shortly after the shock hits. When $A$ increases, there is a negative direct effect on

labor share, as for existing matches. However, there are also indirect effects through the reservation wage $b_{\tau}$ and the market tightness $\theta_{\tau}$, both of which increase. Intuitively, the competition effect through $\theta_{\tau}$ on labor share is positive, since $\mu(\theta) / p(\theta)$ is decreasing in $\theta$. However, the net effect on labor share is ambiguous. The comparative static result in Proposition 5 suggests that the labor share will be increasing in a positive TFP shock provided that the elasticity of the reservation wage with respect to $A$ is greater than one. Since this is true under our calibration $\left(\varepsilon_{b^{*}}(A)=1.41\right)$, we expect to see the labor share for new hires increase in response to a positive TFP shock.

Figure 4 decomposes the IRF for the aggregate labor share (top left panel) into its three determinants: the labor share for new hires (bottom left panel); the labor share for existing hires (bottom right panel); and the output share of new hires (top right panel). The two opposing effects on new and existing hires are key for understanding the aggregate labor share dynamics, and the output share of new hires indexes the relative strength of these two effects.

In response to a positive TFP shock, the aggregate labor share initially drops (top left panel). This is because existing matches, which experience an immediate fall in the labor share (bottom right panel), initially dominate the economy: the output share of new hires $\alpha_{t, T}$ is low (top right panel). In contrast to existing matches, workers hired after the TFP shock are hired in an environment of stronger competition and 


\section{4.3.2. Wage elasticities}

\footnotetext{
${ }^{19}$ Recently, Gertler et al. (2016) find that distinguishing job-to-job flows from unemployment hires may be important. While the presented model abstracts from job-to-job flows, it would be interesting to analyze to what extent the observed labor share dynamics are driven by wage changes of different groups of workers.

${ }^{20}$ See the Appendix for details on the estimation procedure.

${ }^{21}$ Depending on how wages and productivity are measured, estimates of $\eta_{\text {all }}$ range between 0.19 and 0.43 , while estimates of $\eta_{\text {new }}$ vary between 0.54 and 1.07 (see Haefke et al., 2013, for detailed empirical robustness exercises).
} 
the novel features of our model - the competition and cohort effects - contribute to the model's ability to account for the dynamics of the labor share.

We start by using our calibrated model to back out the time path of the two aggregate driving forces: the aggregate TFP $\left(A_{t}\right)$ shock and the investment specific shock $\left(C_{t}\right)$. To do so, we use data on real GDP and the unemployment rate. While both shocks affect the dynamics of the entire model, data on real GDP is primarily informative about the aggregate TFP shock - which directly impacts the output of all matches - and the time path of unemployment is closely related to investment-specific shocks.

The time series for both real GDP and the unemployment rate are logged and HP-filtered. Within the linearized model, the time path of the aggregate shocks are then estimated using the Kalman filter. By construction, the estimated model exactly matches the time path of aggregate output, given by equation (5), and the unemployment rate, given by equation (1). Importantly, the estimated shocks together with the model structure imply time paths for all other model variables, including the aggregate labor share which we focus on below. ${ }^{22}$

The top panel of Figure 5 depicts the observed (HP-filtered) fluctuations in the labor share together with those predicted by the benchmark model. While the modelpredicted labor share is somewhat more volatile, as discussed earlier, the model does very well in capturing the business cycle fluctuations of the labor share throughout the sample period (the correlation coefficient between the two time series is 0.55 ).

\footnotetext{
${ }^{22}$ The Appendix provides further details on the estimation and shows that the time paths of other model variables, not used in the estimation, closely follow those observed in the data.
} 
1 4.4.1. Switching off competition and cohort effects

2 One of the key features of our model is the persistent effect on both production 3 and wages of the degree of firm competition at the time of hiring. This single feature 4 leads to both "competition effects" and "cohort effects". To illustrate the importance 5 of these novel aspects of our model in accounting for the dynamics of the labor share, 6 we consider what happens when this key feature is "switched off".

7

In particular, we consider a "counter-factual" alternative model which is not microfounded, but which retains the steady state equilibrium conditions of our benchmark economy. Specifically, we fix the permanent component of match productivity for all matches to its steady state value, $p\left(\theta_{s s}\right)$. This eliminates the effect on production of firm competition at the time of hiring. We also fix the share of bilateral matches - a measure of the degree of firm competition - to its steady state value, $\mu\left(\theta_{s s}\right)$, and assume that the wage paid in bilateral matches is updated each period. These assumptions eliminate the persistent effect on wages of firm competition at the time of hiring, while keeping the basic wage structure intact. The rest of the benchmark model, including all equilibrium conditions and aggregate shocks, remains the same.

This counter-factual model is similar in spirit to standard Diamond-MortensenPissarides (DMP) model. In such models, there is no dependence on the degree of firm competition at the time of hiring and therefore no "competition" or "cohort" effects. In such models, the share of bilateral meetings is constant (since all meetings are bilateral) and the average match productivity does not vary with the market tightness $\theta_{t}$. Instead, the output of all employment relationships fluctuates only with aggregate TFP shocks, and wages depend only on current labor market conditions (and TFP). All of these DMP-style features are captured in the counter-factual model, while retaining all the equilibrium conditions of our benchmark economy, including its basic wage structure. This experiment therefore gives us a sense of how the competition 
and cohort effects - key to this model but absent from standard DMP models - play

a crucial role in accounting for the cyclical fluctuations in the labor share.

In the counter-factual model, the aggregate labor share $s_{L, t}^{c}$ can be expressed as:

$$
s_{L, t}^{c}=1-\lambda-\left(1-\frac{b_{t}^{c}}{A_{t}}\right) \frac{\mu\left(\theta_{s s}\right)}{p\left(\theta_{s s}\right)},
$$

${ }_{4}$ where $b_{t}^{c}$ is the counter-factual wage paid in bilateral meetings at time $t .{ }^{23}$ Note that there is no distinction between new and existing hires. All "cohorts" face the same wages and labor share (i.e. no cohort effects). Also, neither the average match productivity nor the share of bilateral meetings fluctuate over the business cycle (i.e. no competition effects). The aggregate labor share still fluctuates, however, since it directly depends on aggregate TFP shocks $A_{t}$ and on fluctuations in the counter-factual reservation wage $b_{t}^{c}$. The latter varies over time because it depends on the values of unemployment and employment, and the job finding probability, all of which fluctuate endogenously in the counter-factual economy.

In order to quantify the importance of firm competition at the time of hiring for labor share fluctuations, we redo the above exercise using the counter-factual model which no longer features competition and cohort effects. In particular, we use the counter-factual model to again back out the underlying aggregate TFP and investmentspecific shocks using data on real GDP and unemployment. The labor share implied by the counter-factual model is depicted in the bottom panel of Figure (5).

In contrast to the benchmark economy, the counter-factual model fails to account for the cyclical fluctuations in the labor share. In fact, the labor share predicted by the counter-factual model is essentially uncorrelated with its empirical counterpart (the

\footnotetext{
${ }^{23}$ In equation (41), we have $x_{0 t}=1$, since under our calibration the cut-off productivity for firm participation $x_{t}^{c}$ is always below $x_{\min }=1$.
} 
1 correlation coefficient is 0.01). Therefore, the novel feature of our model - namely, 2 the direct competition between firms to hire workers and the resulting cohort effects 3 - is crucial for understanding the cyclical fluctuations of the U.S. labor share, both 4 qualitatively and quantitatively.

\section{5. Conclusion}

6 While the relative constancy of factor shares has been a stylized fact in macroeco7 nomics for decades, factor shares are not constant in the data. Importantly, movements 8 in the labor share systematically respond to TFP shocks and such movements have im9 portant implications for aggregate dynamics (Rios-Rull and Santaeulalia-Llopis, 2010).

This paper contributes to our understanding of the business cycle properties of the labor share. We develop a tractable dynamic search and matching model in which heterogeneous firms compete to hire workers. Such competition endogenizes both the aggregate production technology and the division of output between workers and firms. We show that the model can account well for both the counter-cyclicality of the U.S. labor share and its overshooting pattern following TFP shocks, as well as its time path.

While the focus of this paper is on understanding the labor share, the model makes a host of other predictions regarding important issues in macroeconomics. For example, how do fluctuations in the degree of firm productivity dispersion affect labor productivity, unemployment, and the wage distribution? The model provides an integrated framework for addressing such questions. Moreover, the vintage structure of the model provides a way of studying cohort effects. In particular, it directs attention to the composition of the employment pool with respect to labor market conditions at the time of hiring. Given the existing evidence on firm and worker cohort effects, it would be interesting to use the model to examine the persistent scarring effects of entering the labor market during a downturn. These questions are left for future research. 


\section{References}

Bentolila, S., Saint-Paul, G., 2003. Explaining Movements in the Labor Share. Contributions to Macroeconomics 3.

Bils, M., 1985. Real wages over the business cycle: Evidence from panel data. Journal of Political Economy 93, 1-76.

Blanchard, O.J., 1997. The Medium Run. Brookings Papers on Economic Activity 2, 89-158.

Canova, F., Lopez-Salido, D., Michelacci, C., 2013. The Ins and Outs of Unemployment: An Analysis Conditional on Technology Shocks. Economic Journal 123.

Choi, S., Rios-Rull, J.V., 2009. Understanding the Dynamics of Labor Share: The Role of Noncompetitive Factor Prices. Annals of Economics and Statistics , 251-277.

Colciago, A., Rossi, L., 2015. Firm Dynamics, Endogenous Markups, and the Labor Share of Income. Macroeconomic Dynamics 19, 1309-1331.

Elsby, M., Michaels, R., 2013. Marginal jobs, heterogeneous firms and unemployment flows. American Economic Journal: Macroeconomics 5, 1 - 48.

Elsby, M.W., Hobijn, B., Şahin, A., 2013. The decline of the us labor share. Brookings Papers on Economic Activity 2013, 1-63.

Fisher, J., 2006. The Dynamic Effects of Neutral and Investment-Specific Technology Shocks. Journal of Political Economy 114, 413-451.

Gertler, M., Huckfeldt, C., Trigari, A., 2016. Unemployment Fluctuations, Match Quality, and the Wage Cyclicality of New Hires.

Gomme, P., Greenwood, J., 1995. On the cyclical allocation of risk. Journal of Economic Dynamics and Control 19, 91-124.

Haefke, C., Sonntag, M., van Rens, T., 2013. Wage Rigidity and Job Creation. Journal of Monetary Economics 60, 887-899.

Jones, C.I., 2005. The Shape of Production Functions and the Direction of Technical Change. Quarterly Journal of Economics 120, 517-549.

Jung, P., Kuester, K., 2015. Optimal Labor Market Policy in Recessions. American Economic Journal: Macroeconomics 7, 124-156.

Justiniano, A., Primiceri, G., 2008. The Time Varying Volatility of Macroeconomic Fluctuations. American Economic Review 98, 604-641.

Karabarbounis, L., Neiman, B., 2014. The Global Decline of the Labor Share. Quarterly Journal of Economics 129, 61-103.

King, R.G., Watson, M.W., 2012. Inflation and unit labor cost. Journal of Money, Credit and Banking 44, 111-149.

Lagos, R., 2006. A Model of TFP. Review of Economic Studies 73, 983-1007.

Lopez-Salido, D., Michelacci, C., 2007. Technology shocks and job flows. Review of Economic Studies 74, 1195-1227. 
1 Mangin, S., 2017. A Theory of Production, Matching, and Distribution. Journal of 2 Economic Theory (forthcoming).

${ }_{3}$ Oreopoulos, P., Heisz, A., von Wachter, T., 2012. The Short- and Long-Term Ca4 reer Effects of Graduating in a Recession. American Economic Journal: Applied 5 Economics 4, 1-29.

6 Piketty, T., 2014. Capital in the Twenty-First Century. Belknap Press, Cambridge, Massachusetts.

8 Piketty, T., Zucman, G., 2014. Capital is back: Wealth-income ratios in rich countries 9 1700-2010. Quarterly Journal of Economics 129, 1255-1310.

10 Rios-Rull, J.V., Santaeulalia-Llopis, R., 2010. Redistributive Shocks and Productivity

11 Shocks. Journal of Monetary Economics 57, 931-948.

12 Sedláček, P., Sterk, V., 2017. The Growth Potential of Startups over the Business Cycle. American Economic Review 107, 3182-3210.

14 Shimer, R., 2005. The Cyclical Behavior of Equilibrium Unemployment and Vacancies. American Economic Review 95, 25-49.

16 Syverson, C., 2004. Product Substitutability and Productivity Dispersion. Review of 17 Economics and Statistics 86, 534-550. 
Table 1: Calibrated parameters and their respective targets

\begin{tabular}{|c|c|c|c|}
\hline & parameter & value & target/source \\
\hline \multicolumn{4}{|c|}{ household and labor market } \\
\hline$\beta$ & discount factor & 0.996 & annual interest rate $4 \%$ \\
\hline$z$ & value of non-market activity & 0.320 & labor share $68 \%$, RS (2010) \\
\hline$\delta$ & separation rate & 0.050 & unemployment rate $5.8 \%$, BLS \\
\hline $\bar{C}$ & vacancy posting cost & 6.361 & job finding rate $45 \%$, Shimer $(2005)$ \\
\hline \multicolumn{4}{|c|}{ firm productivity distribution $G(x)$} \\
\hline$x_{\min }$ & minimum & 1 & normalization \\
\hline$\lambda$ & shape parameter & 0.27 & $90-10$ TFP range 0.83, Syverson (2004) \\
\hline \multicolumn{4}{|c|}{ aggregate shocks } \\
\hline$\rho_{A}$ & TFP, persistence & 0.931 & output persistence, BEA \\
\hline$\sigma_{A}$ & TFP, standard deviation & 0.007 & output volatility, BEA \\
\hline$\rho_{C}$ & investment-specific, persistence & 0.906 & labor productivity persistence, BLS \\
\hline$\sigma_{C}$ & investment-specific, volatility & 0.033 & labor productivity volatility, BLS \\
\hline
\end{tabular}


Table 2: Business cycle statistics

\begin{tabular}{|c|c|c|c|c|c|c|c|c|c|}
\hline & & \multicolumn{4}{|c|}{ U.S. data } & \multicolumn{4}{|c|}{ model } \\
\hline & & $Y$ & $u$ & $\theta u$ & $m$ & $Y$ & $u$ & $\theta u$ & $m$ \\
\hline \multicolumn{2}{|c|}{ relative volatility } & 1.2 & 8.7 & 10.2 & 5.7 & 1.3 & 5.6 & 4.1 & 6.7 \\
\hline \multirow{3}{*}{ correlations } & $Y$ & 1 & -0.83 & 0.89 & 0.82 & 1 & -0.63 & 0.51 & 0.61 \\
\hline & $u$ & & 1 & -0.91 & -0.91 & & 1 & -0.81 & -0.96 \\
\hline & $\theta u$ & & & 1 & 0.91 & & & 1 & 0.93 \\
\hline
\end{tabular}

Notes: The table reports the standard deviations of labor market variables relative to that of labor productivity ("relative volatility") and the associated correlation matrix both for the U.S. data and the model. The sample period considered runs from 1954Q1 to 2004Q4. $Y$ refers to real GDP, $u$ is the number of unemployed, $\theta u$ is the number of vacancies, and $m$ is the job finding probability. All data are taken from Rios-Rull and Santaeulalia-Llopis (2010), except for the job finding probability, which is taken from Shimer (2005). The data are logged and HP filtered with a smoothing coefficient of 1600. The simulated data from the model is treated in the same way and has the same sample period length. 
Figure 1: Impulse response functions of labor market variables
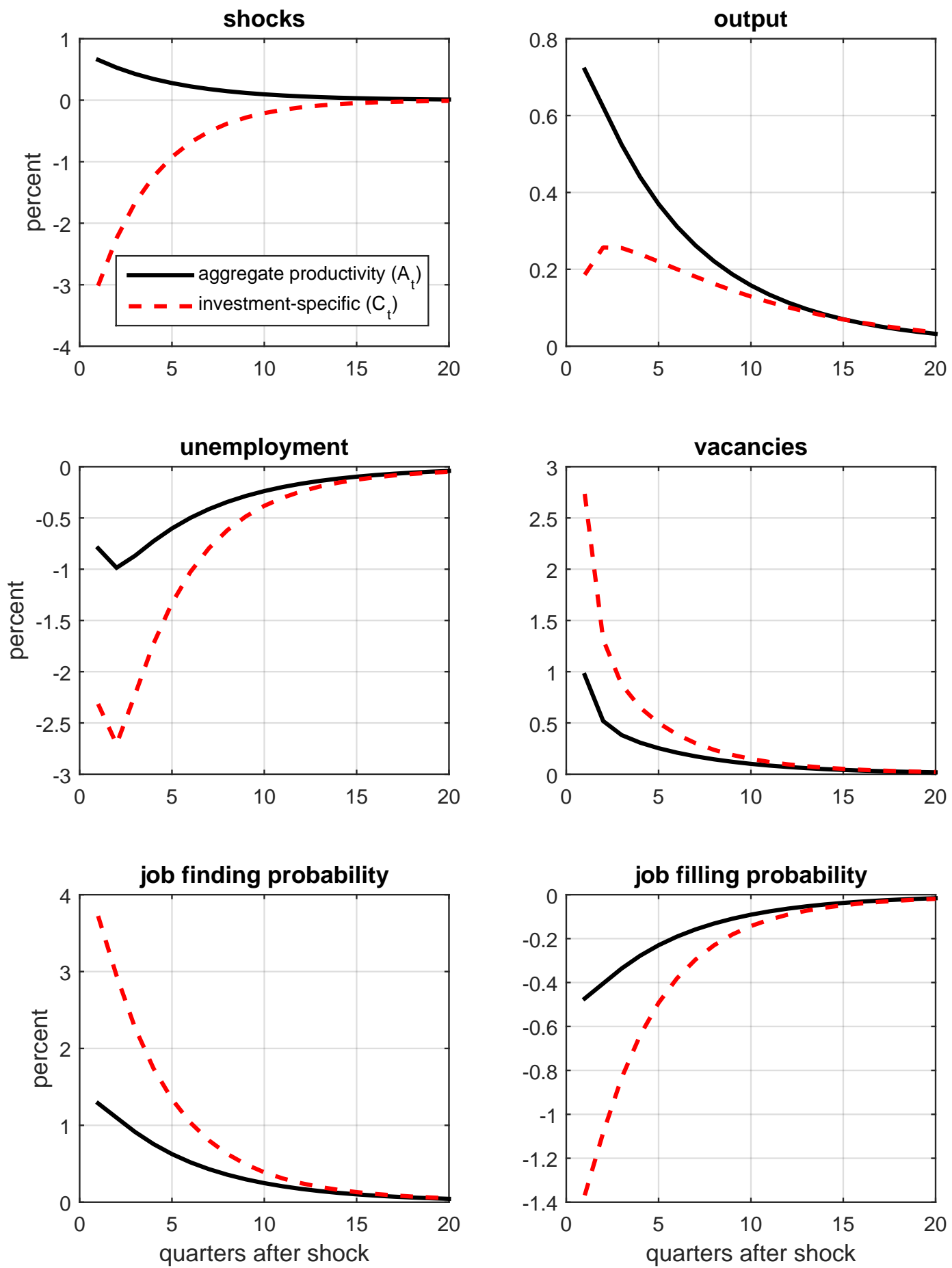

Notes: Impulse response functions to expansionary one-standard-deviation shocks to aggregate TFP (black solid line) and investment-specific technology (red dashed line). All variables are expressed in percent deviations from their respective steady state values. 
Figure 2: Impulse response function of labor productivity

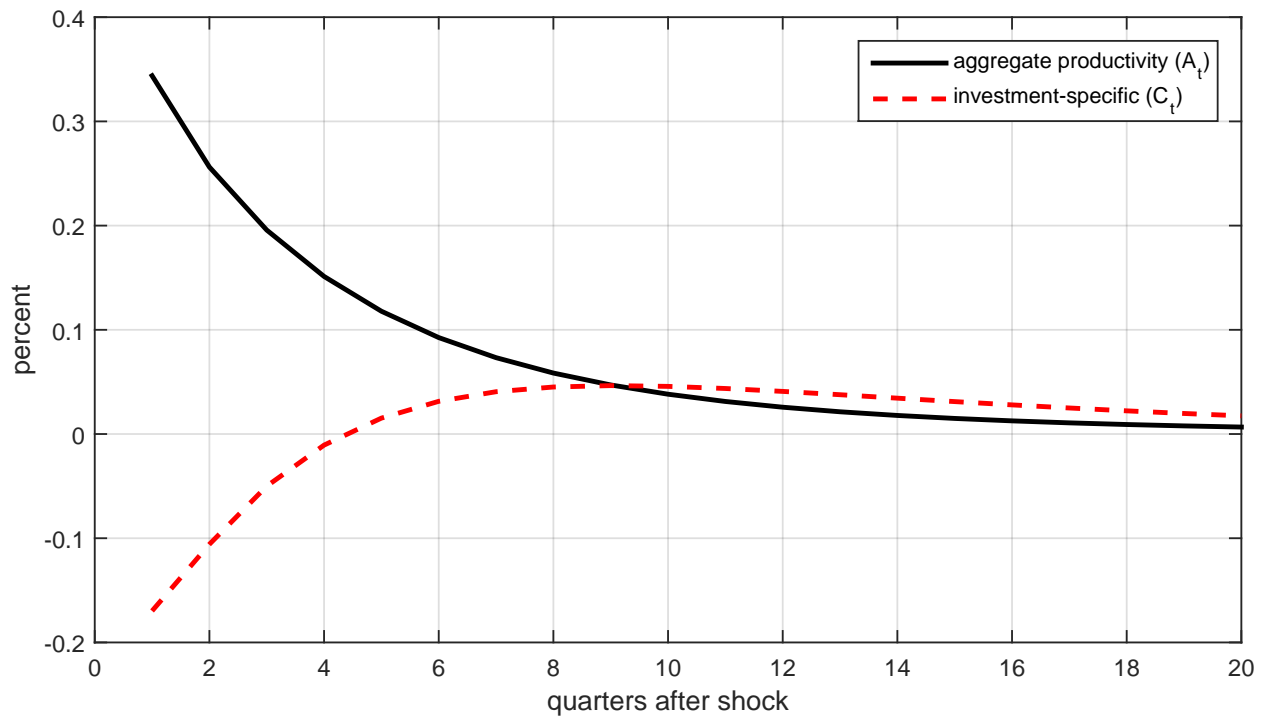

Notes: Impulse response function to expansionary one-standard-deviation shocks to aggregate TFP (black solid line) and investment-specific technology (red dashed line). Labor productivity is expressed in percent deviations from its steady state values. 
Figure 3: Impulse response function of the labor share

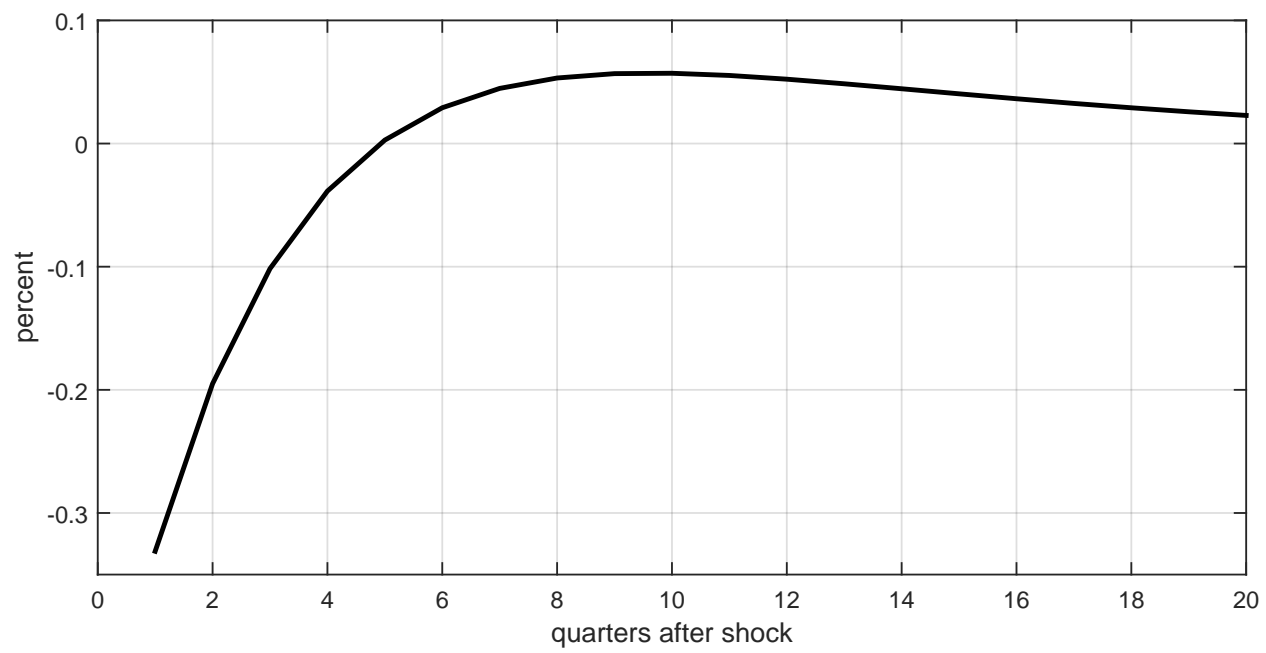

Notes: Impulse response function to an expansionary one-standard-deviation shock to aggregate TFP expressed as percent deviations from steady state. 
Figure 4: Impulse response function for new hires and existing matches
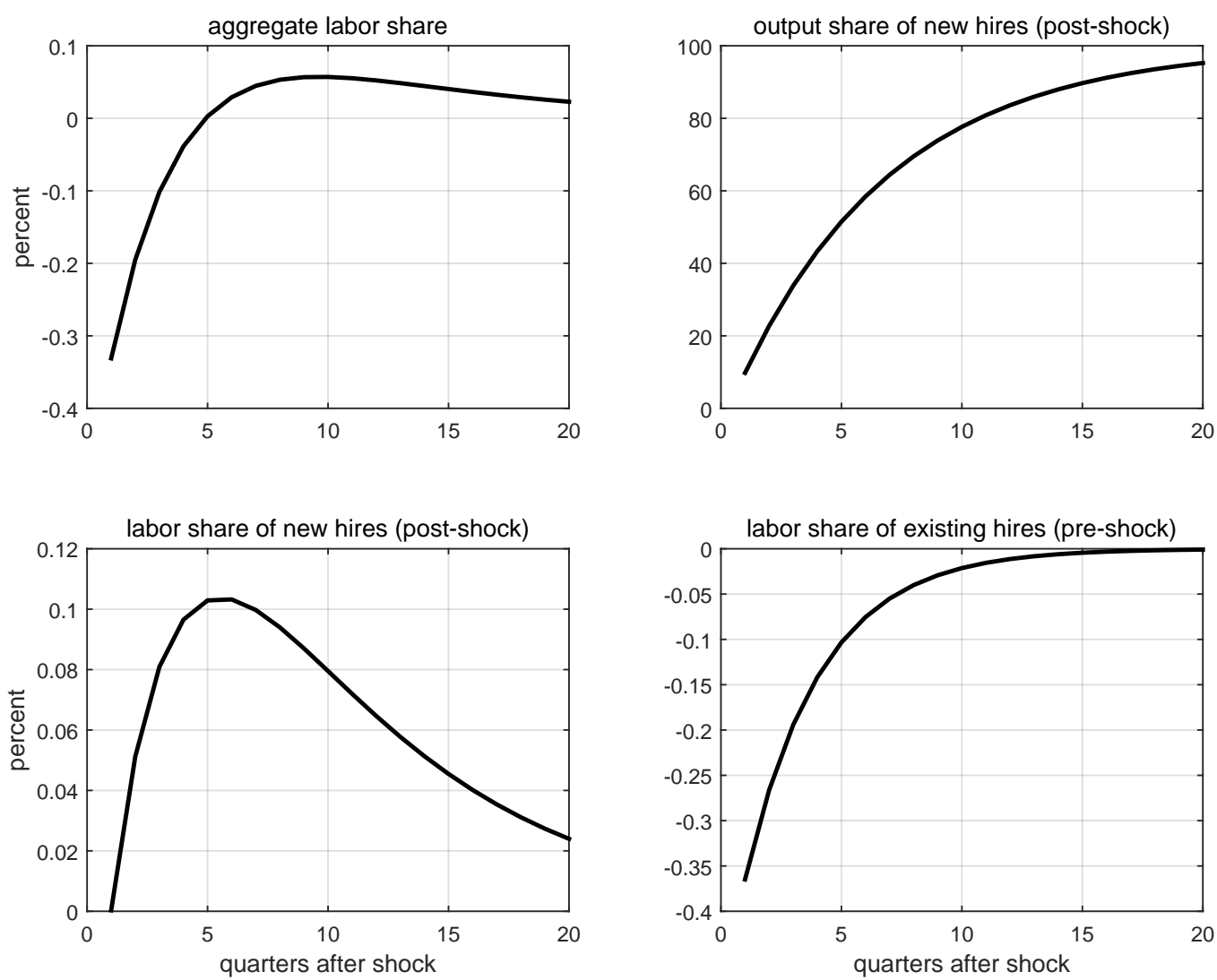

Notes: Impulse response function to an expansionary one-standard-deviation shock to aggregate TFP expressed as percent deviations from steady state. "Labor share of new hires (post-shock)" and "labor share of existing hires (pre-shock)" refer to, respectively, the average wage-to-output ratios in employment relationships formed after and before the aggregate TFP shock hits the economy. "Employment share of new hries (post-shock)" refers to the share of employment relationships formed after the aggregate TFP shock. 
Figure 5: Time path of the labor share: data and model
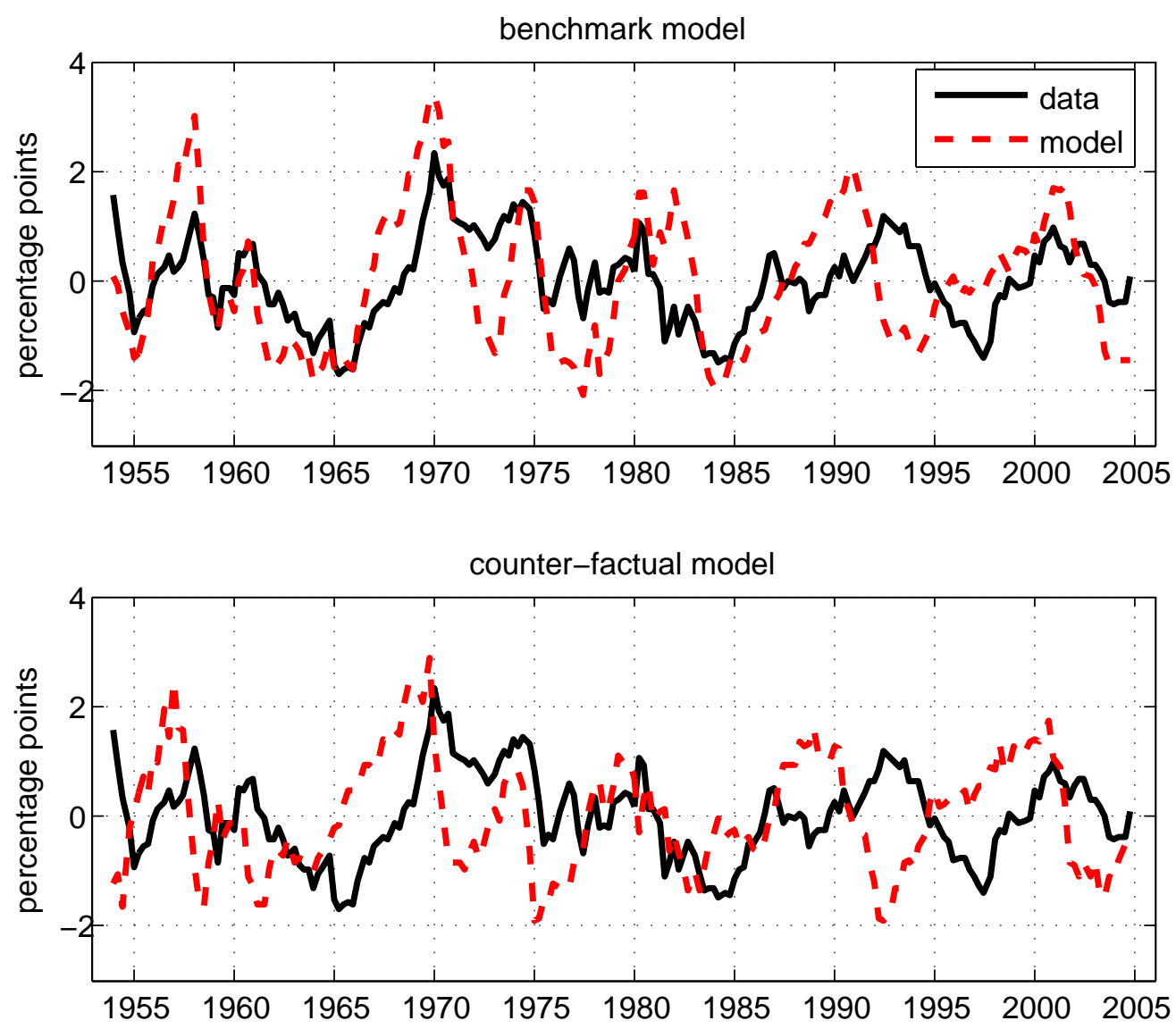

Notes: The labor share data is taken from Rios-Rull and Santaeulalia-Llopis (2010), HP-filtered. The top panel shows the model-predicted labor share in the benchmark model and the bottom panel shows the counter-factual model-predicted labor share without competition and cohort effects. Both modelpredicted time-series are constructed based on aggregate TFP and investment-specific shocks backed out from the respective models using the Kalman filter and data on real GDP and the unemployment rate. All variables are expressed in percentage point deviations from their respective trends. 